Anales del Seminario de Historia de la Filosofía ISSN-e 1988-2564

http://dx.doi.org/10.5209/ASHF.58788

\title{
G. Krüger: una re-lectura de los diálogos platónicos desde su propia concepción de mýthos
}

José Alejandro Fernández Cuesta ${ }^{1}$

Recibido: 01 de febrero de 2018 / Aceptado: 19 de septiembre de 2018

Krüger, Gerhard. Eros y mito en Platón. Traducción de Miguel Oliva Rioboó y Santiago Sanjurjo. Primera edición. Madrid: Escolar y Mayo Editores, 2017. (ISBN: 978-84-17134-18-1).

Platón es, sin duda alguna, uno de los grandes filósofos que ha generado más posibilidades interpretativas respecto de la manera en cómo abordar su obra a lo largo de toda la historia de la filosofía; pues ya en la Antigüedad misma se discutía polémicamente acerca de la forma correcta $\mathrm{o}$, al menos, mejor posible, de estudiar sus diálogos. A partir del siglo XX los avances, no solamente arqueológicos o papirológicos, sino científicos y técnicos en general y, por ende, filológico-históricos en concreto, permiten la proliferación de numerosas perspectivas nuevas desde las cuales abordar de un modo innovador la lectura de los diálogos platónicos.

Gerhard Krüger, nacido en Berlín en 1902, estudia filosofia junto a Paul Natorp en Marburgo tras abandonar sus estudios de historia en Tubinga, y será allí, precisamente en Marburgo, donde vivirá la crisis del neokantismo a través de la discusión entre el propio Natorp y Hartmann. Discusión que marcará su doctorado, en 1925, realizado de la mano de éste y titulado Kants Lehre von der Sinnesaffektion. Krüger establecerá estrecha relación, a partir de los debates que mantuvieron Heidegger y Bultmann que influirán en su posicionamiento respecto de la hermenéutica-, con Gadamer, el cual llegará a decir, en referencia a Eros y mito en Platón, que «puede incluirse entre las más perdurables y magistrales aportaciones a nuestro diálogo con los griegos $»^{2}$. La presente obra, uno de los principales trabajos de Krüger sobre Platón, en su completitud fue titulada Comprensión y pasión: La esencia del pensamiento platónico (Einsicht und Leidenschaft: Das Wesen des platonischen Denkens) y vio la luz en 1973 como una cuarta edición ${ }^{3}$. No obstante, en palabras de Richard Schaeffler, editor, "aquí se presenta el tratado introductorio sobre "Eros y mito" publicado como separata y desligado de la interpretación de un determinado diálogo platónico. La motivación para hacerlo así partió de Hans-Georg Gadamer»»

Universidad Complutense de Madrid

josealef@ucm.es

ORCID: 0000-0002-9637-9291

2 Gadamer, Hans-Georg. Philosophische Lehrjahre, Frankfurt, 1977.

3 La publicación original data de 1939 y la última de 1992.

4 Krüger, Gerhard. Eros y mito en Platón. Traducción de Miguel Oliva Rioboó y Santiago Sanjurjo. Primera 
En este sentido el libro Eros y mito en Platón quedará no tanto descontextualizado como sí dotado de una cierta independencia que permitirá, en este último sentido, ampliar sus posibilidades aplicativas o referenciales más allá de lo que el propio autor indicaría en un primer momento -a saber, la lectura del mito de Eros principalmente en el Diálogo de El Banquete de Platón- para pasar a constituir la búsqueda de «un acceso a toda la filosofía platónica» $\aleph^{5}$ que, aunque parta de dicha interpretación como punto de arranque, pueda, finalmente, emanciparse de ella para logar un sentido global -que se irá alcanzando a lo largo del desarrollo del libro yendo desde Eros hasta la concepción platónica general del mýthos-. Para ello dispone este, en primer lugar, de una introducción capaz, precisamente, de matizar todas estas cuestiones $\mathrm{y}$, en segundo lugar, del propio desarrollo del libro dividido en cinco puntos de análisis recursivo que irán hilando lo que podríamos llamar, la cuestión platónica -en un sentido muy amplio-, avanzando así desde el punto de partida más concreto -el mito mismo de Eros en Platón- hasta el colofón de la clave interpretativa misma de la obra en general de Platón -la lectura de sus diálogos desde la peculiaridad que dicho mito supone en el propio Platón así como el papel que juegan en ellos los mitos platónicos y el trato que de la poesía pueda hacer el filósofo-coronada con los ejemplos justificativos o, mejor dicho, argumentativos, más ilustrativos rastreados en la totalidad de dicho corpus: El problema moral y religioso de Eros, Eros como poder mítico, Eros en comparación con los dioses cósmicos, la crítica platónica del mito cósmico y de su poesía y, finalmente, la peculiaridad de eros y la poesía platónica. Al final de esta parte que hemos convenido en llamar el propio desarrollo del libro se anexan las notas que se han considerado no «directamente necesarias para la comprensión del texto» ${ }^{6}$ así como un epílogo y unas líneas biográficas del autor-estos dos últimos, redactados por el editor alemán Richard Schaeffler-.

Krüger, buscando una definición platónica de la filosofía a través del mito de Eros, no se limita a estructurar la cuestión acerca de dicha definición de filosofía dentro de la propia obra de Platón, sino que dibuja, precisamente, cuál es el sentido que esa filosofía, platónica, aporta precisamente a la cuestión misma de su definición. La interpretación de la definición platónica de filosofía propuesta por Krüger revela, así, una posibilidad interpretativa de la propia filosofía platónica como un modo de acceso a sus diálogos muy concreto. El hecho, innegable, de que son una gran pluralidad ${ }^{7}$ las definiciones platónicas de filosofía que en su obra nos han llegado revela, ya de entrada, una complicación de comprensión objetiva que incita a Krüger a tratar de dejar que sea el propio Platón quien nos dé cuenta de esta cuestión y, para ello, se habrá de focalizar, en un primer momento, la atención en la figura mítica de Eros. ${ }^{8}$

edición. Madrid: Escolar y Mayo Editores, 2017., p. 130.

Ibid., p. 13.

Ibid., p. 121.

Cfr. infra. Nota a pie de página 11.

Esta tarea habrá de comenzar con una contextualización de carácter histórico que permita abordar con rigor, posteriormente, la propia figura de Eros ya desde una perspectiva filosófica - o, mejor dicho, que permita abordar la propia filosofía platónica desde la perspectiva que el estudio del trato platónico de Eros revele--. Rescatar entonces la figura de Eros como clave para abordar y comprender la filosofía que se desarrolla a lo largo de los diálogos platónicos implica tratar de descifrar esta enigmática figura sin presuponerle, de entrada, ninguna, por así decirlo, filosofía concreta. Hay que comenzar atendiendo a lo que de Eros se nos dice en los diálogos, pero no desde una perspectiva moderna -psicológica, ético-estética o pedagógica-ni, mucho menos, desde una perspectiva platónica - pues aún no sabríamos, por lo que hemos apuntado, qué perspectiva podría ser tal-. No se trata de comprender el sentido de Eros desde la filosofía de Platón. Se trata de esclarecer la filosofía misma 
En ese sentido se desmarca la interpretación de Krüger del resto de propuestas que se suceden desde el siglo XIX para la comprensión de la obra de Platón encabezadas por Schleiermacher por un lado y Hermann por otro- las cuales son tomadas aquí, aunque como verdaderos estudios de Platón -pues todos los anteriores estaban, en realidad, demasiado cerca aún de su filosofía-, como insuficientes de cara a una lectura apropiada de los diálogos. La historiografía moderna ha sido capaz de sustituir a la tradición, pero, aunque ésta tuviera el inconveniente de estar inmersa en la falta de conciencia histórica, posibilitaba, no obstante, un vínculo con el pasado en tanto que comparten las mismas inquietudes - no adulterando el acceso-. La investigación moderna, no obstante, sí que adultera; y es que en el estudio de Platón se pierde en la modernidad la propia perspectiva filosófica ${ }^{9}$. La prueba de esto la vemos en la escisión de los estudios sobre Platón en, por un lado una perspectiva filosófica - pretendiente de y enmarcada en un conocimiento objetivo- y, por otro lado, una filológica que, atendiendo a los hechos históricos, dibuja a un Platón a-filosófico construido a partir de meros datos biográficos e históricos. La pretensión acertada ha de ser la de acceder a Platón de forma filosófica utilizando, eso sí, las herramientas disponibles para entender ese contexto histórico ${ }^{10}$ pero, claro está, no quedándose ahí. Nartop ${ }^{11}$ y Stenzel ${ }^{12}$ consiguen que se renuncie acertadamente a la interpretación por la cual Platón ha de ser sistemático -idea moderna- aunque para ello se margina precisamente el elemento filosófico, lo cual constituirá, en último término, la misma aporía que la propia filosofía moderna plantea tal y como ya hemos mencionado. Así las cosas, el método de interpretación que se propone ha de comenzar por una interpretación de Eros, aunque no deba detenerse ahí. Prescindiendo de otras definiciones, aún platónicas, de filosofía ${ }^{13}$ y centrándose en la recogida en el Banquete ${ }^{14}$ en la cual se trata a Eros como ese «gran dáimon» descrito como «filósofo» que hace que la filosofía sea descrita como «la pasión amorosa del hombre que se eleva progresivamente desde la corporalidad de lo bello hasta la “mismísima belleza" divina»"

de los diálogos platónicos desde el trato que en ellos se hace de Eros y su mito.

$9 \quad$ Kant pone fin a la metafísica entendida como ciencia y, con ello, la filosofía moderna no solo deja de posibilitar el acceso - como ya venía sucediendo desde Descartes- sino que llega a impedirlo. Krüger propone, no obstante, ciertas perspectivas modernas que tratan de posibilitarlo al tomarse en serio la cuestión como pueden ser la de Schelling -y su trato de los mitos platónicos- o Hegel -y su reavivamiento de la dialéctica metafísica- aunque dicha posibilitación siempre se planteará desde la distancia resultando, en ese sentido, inútil para lo que aquí se pretende lograr.

10 Aunque Krüger rechazará, de antemano y en este contexto, cualquier lectura de los diálogos platónicos en consonancia con las doctrinas platónicas conocidas como ágrapha dógmata, quedará bosquejada, al final de esta exposición, la idea de la clara no-incompatibilidad entre la propuesta inicial de Krüger y una lectura de los diálogos platónicos que tenga a éstas doctrinas en cuenta, planteando entonces la cuestión de la no-necesidad de exclusión de su lectura aún cuando lo que se pretenda sea iniciar un acceso a Platón filosóficamente en los exactos términos que propone Krüger. Respecto de estas ágrapha dógmata dirá que «sea lo que sea lo que signifique esta doctrina: dado que los diálogos no evitan en modo alguno la oportunidad de hablar de lo que, por excelencia, es la filosofía, parecería que están pidiendo ser comprendidos en primera instancia a partir de la definición que de ella hacen, y queda abierta la pregunta de si el testimonio de Platón en la Carta VII, por una parte, y la existencia de aquella doctrina esotérica, por otra, son compatibles con la exposición que ofrecen los diálogos». Krüger retornará a esta cuestión en su Einsicht und Leidenschaft: Das Wesen des platonischen Denkens, pp. 274 y ss.

11 Natorp, Paul. Platos Ideenlehre; eine Einführung in den Idealismus, Leipzig, 1903.

12 Stenzel, Julius. Studien zur Entwicklung der Platonischen Dialektik von Sokrates zu Aristoteles: arete und diairesis. Princeton, 1917.

13 Como las expuestas en la Apología (20d), Fedón (64a), República (473 d-e, 521c, 531 d), Teeteto (176 a), etc.

14 Banquete, 203 d-e, 204 b y 210 a.

15 Krüger, op. cit., p. 11. 
En el Banquete ${ }^{16}$ se presenta el propio texto como narración de los diálogos sobre Eros (erotikoì lógoi), la narración de Eros como objeto de estudio pero, también, se muestra la presentación de los personajes estructurados con rasgos eróticos ${ }^{17}$, y es que en el último discurso de Alcibíades ${ }^{18}$ ya no se dedicará el texto a Eros sino a Sócrates -el propio amor de Alcibíades- y que, en ese sentido profundo engloba a Eros pero que, superficialmente, pone en relación a ambos personajes. La presentación de dichos personajes como eróticos será relevante por cuanto causará, en el lector moderno, una cierta extrañeza moral que deberá aclararse ${ }^{19}$.

Para tal aclaración Krüger parte del personaje de Lisias ${ }^{20}$, quien toma a Eros como afán humano; preocupación plenamente moral por el bienestar del amado. Esta extraña figura que podría parecer incluso negativa si se tornase como algo semejante a indecencia acechante, obliga a darse cuenta de que esa extrañeza que Eros causa, en tanto que algo divino, es una extrañeza religiosa. Krüger insistirá en que el discurso mítico de Eros no se debe tomar como una mera analogía de algo así como un ansia de saber o del amor como comportamiento característicamente humano, pues esto serán cuestiones mundanas y se debe recordar que la extrañeza es, en todo caso, religiosa. Partiendo de este punto se revela entonces ${ }^{21}$ que la problemática en torno a la cual se estructurará la extraña figura mítica de Eros en Platón no será otra más que la de la relación entre la filosofía y la religión; relación que para nosotros se planteará siempre como una contraposición ${ }^{22}$.

Al tratar de decir qué es la filosofía, el filósofo explicará en qué consiste su pensamiento, clarificándolo, ora desde sí mismo -lógica filosófica-, ora «tomando como punto de partida un comportamiento humano diferente del que primeramente podemos comprender ${ }^{23}$. Pues bien, Platón toma una tercera vía y opta por no aclarar en ese sentido: presenta la esencia de la filosofía bajo una forma mítica como «recuerdo de una vida del alma preexistente y como una pasión amorosa por la belleza de lo divino» ${ }^{24}$. El vínculo existente entre filosofía y religión es el contrario del nuestro: no se trata de una religión entendida filosóficamente sino, por el contrario, de tener que entender la filosofía misma de forma religiosa. Ahora bien, la filosofía que se está poniendo en juego en la obra platónica tampoco es, ni mucho menos, lo que nosotros podemos entender por religión. Se trata de la religión pagana, la religión manifestada a través del mito. Y, atendiendo a esto último, será fácil ver cómo, al entender que la filosofía siempre ha crecido criticando el mito, no hay, en realidad, tanta diferencia entre la filosofía moderna y la platónica por cuanto Platón utilizará ese mismo mito pagano -y esa relación entre filosofía y la religiónpara, yendo en su contra - pero sin poder distanciarse de forma absoluta- enmarcar

\footnotetext{
Banquete, $172 \mathrm{~b}$.

Lo cual quedará claro también en 177 d-e.

Banquete, 222c.

19 Decir que se debe a una mera concepción radicalmente distinta de la noción de amor es una simplificación. Y es que Sócrates aprende de Diotima que el papel rector de Eros en la procreación misma es un asunto divino.

22 Pues aunque se respete la religión desde la hegemonía de la razón, dicho respeto partirá, precisamente, de un posicionamiento privilegiado de la filosofía. Respetando la religión, como Kant o Leibniz, o tratando de llevar a cabo una unificación, como Hegel, siempre estará pendiente la cuestión de la explicitación de la contradicción misma.

23 Krüger, op. cit., p. 36.

$24 \quad$ Ibid., pp. 36-37.
} 
su propia filosofía en el extraño mito de Eros. Puntos de contacto entre Platón y la filosofía moderna, en ese sentido, serán su crítica a los poetas -como crítica al mito- así como la creación de sus propios mitos -como ficciones libres por un lado pero, por otro, no exentas de ironía- siempre como algo serio (spoudé) y a la vez aproximándose a la «broma» ${ }^{25}$, al juego (paidia). Platón será crítico con los mitos tradicionales aunque utilice el mýthos para reemplazar al lógos en aquellos pasajes que sean, precisamente, importantes por cuanto traten los temas más elevados ya que será, esa forma de decir, la única que permitirá hablar de lo más alto y absoluto -es decir, lo divino-. Es por esto, precisamente, que en el Banquete se muestra la esencia de la filosofía, concretamente, a través de Eros por medio de mitos -aunque no cualesquiera mitos-.

Para poder salvar las distancias con el paganismo antiguo debemos aceptar que las acciones de los dioses repercuten en el comportamiento humano y que, en ese sentido, Eros representa la divinización de un comportamiento que conocemos muy bien. Y es que quien está tocado por el amor se comporta junto a lo que desea. Pues bien, dicho comportarse se inserta en un estado de ánimo en el que nos veremos enmarcados sin posibilidad de decisión -ese estado de ánimo en que se inserta ese comportamiento será muy concreto y no elegido al azar por Platón a la hora de, precisamente, tomar distancia del mito pagano-. La libertad parece verse reducida a un mero asentimiento entonces hasta casi desaparecer frente a la supremacía del amor -lo que tiene de divino-, la cual nos sobreviene como una fuerza que se presenta como algo en sí y que es capaz de actuar por sí misma. Para nosotros se trata de algo exagerado -y absurdo si ni siquiera somos capaces de llevar a cabo la aceptación anterior-debido a que, para tal sobrecogimiento, debemos añadirle a Eros, precisamente, una dependencia religiosa: ¿se puede experimentar independencia absoluta en el pensamiento moderno a la vista de los dioses del paganismo? Para Krüger todos los intentos de ruptura de esta barrera que han pasado por pretender recuperar esa experiencia religiosa de la antigüedad, fracasarán.

Así pues, en ese comportamiento enmarcado en el estado de ánimo en que se ve inserto sin posibilidad de decidir, el hombre se somete en su totalidad, pero no por completo. El hombre moderno siempre conservará su independencia, y es que Eros nunca podrá devorar la posibilidad misma de libertad que viene dada con la esencia de nuestra condición humana -nunca esclavizará-. Y, ya que ni siquiera para la ilustración la libertad tendrá hegemonía absoluta, nunca estaremos sometidos totalmente en tanto que la autoconciencia a la que aludimos con la palabra «yo» no tiembla - palabra, por otro lado, desconocida para los griegos en los términos en que nosotros la asumimos-. Es entonces cuando Krüger asume que la comprensión de la pasión pasa por la pregunta acerca de la razón misma planteada en los términos de su pérdida: perder el entendimiento, perder el dominio de sí mismo, es literalmente la «pasión», el «sentido que delira» ${ }^{26}$ (Wahnsinn). Por esto mismo Platón contrapone el clarividente dominio de uno mismo (sophroneín) al sentido religioso que la misma locura de la pasión alberga en sí misma y establece que ${ }^{27}$ locura (manía) no será un mal -ya que por ella nos llegarán grandes bienes - sino un theía dosis. Así entenderemos que hay una manía -aquella que no sea consecuencia de la enfermedad humana-

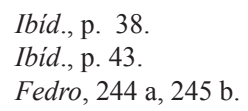


que tendrá lugar «a través de la supresión por la divinidad de los usos establecidos» (hypò theías éksallagés tón eiothóton nomímon) ${ }^{28}$.

Los delirios provocados por Eros nunca suprimirán ni desanclarán el yo, al contrario, lo liberarán y elevarán. La comprensión de Eros en Platón debe radicar en comprender, precisamente, a Eros desde sí por cuanto él mismo motiva, siendo él de quien «en verdad procede toda la acción» ${ }^{29}$. Para Platón ${ }^{30}$ el amante es apartado de los menesteres humanos (anthrōpínōn spoudasmátōn) y es volcado hacia lo divino (kaì pròs tō theío gignómenos) hasta ser tachado de perturbado por quienes no se han dado cuenta de que está imbuido por un dios (enthousiátsōn) ${ }^{31}$. Cuando la razón suficiente de comprensibilidad se halla fuera de la soberanía del yo es cuando nos encontramos ante una experiencia que se vuelve religiosa. La explicación de la esencia del alma narrada en el Fedro ${ }^{32}$ y el mito del carro alado explicitarán esa relación inversa entre «el carácter personal de los poderes que actúan fuera de nosotros» $\mathrm{y}$ « la conciencia de la libertad fundamental interior». Con el mito se muestra que la naturaleza misma del alma consistirá en su espontaneidad -donde se postula la libertad- y que el alma humana, como imagen de la divina - perfecta-, mostrará por ello una carencia respecto de la autenticidad de tal espontaneidad. Platón explica, dentro de su crítica al mito, que la experiencia de la pasión conduce a una idea antropomórfica de los dioses ofreciendo una genealogía del discurso religioso pagano sobre el dios ${ }^{33}$. Concienciándonos de esta dependencia esencial podremos re-conocer la existencia de un ser divino. Lo que Platón está haciendo es una apología de la Wahnsinn divina.

Y, puesto que hablar acerca de qué es el alma es cuestión divina, habremos de limitarnos a decir a qué se parece. Debemos limitarnos a un punto de vista limitado por esa misma imperfección anímica: el alma humana se hallará ligada al cuerpo así como el conocimiento a las imágenes sensibles. La cosmovisión recogida en el Timeo ${ }^{34}$ no propiciará imágenes exactas sino argumentos ilustrativos (eikótas); aceptar la naturaleza humana implica el uso de esos discursos míticos que sean meramente ilustrativos o probables (tòn eikóta mýthon) ya que para las preguntas que nos sobrepasan el mito será la única forma de conocimiento adecuada -por cuanto quien requiere de él es cognoscitivamente limitado-. Y es por ello que el mito del alma incluye en su propio argumento la justificación de la forma que adoptará:

28 Ibid., 265 a.

29 Y no, por el contrario, «en vista del austero pensamiento implicado en lo "serio" de la existencia dueña de sí». Cfr. Krüger, op. cit., p. 44.

$30 \quad$ Fedro, 249 c-d.

31 Si antes decíamos que a través de la manía nos llegan grandes bienes, debemos ver que comprender a Eros como un dios pasará por reconocer, precisamente, sus efectos como tales bienes. Se trata de asumir que la verdad y la riqueza de lo humano consisten en la posesión de tales bienes -y otros semejantes- y no, por el contrario, en alcanzar la dignidad que confiere la libertad racional ya que desde Kant se entiende que: « [la experiencia en general] no es sólo la percepción de lo verdadero, sino también una concepción y una comprensión de lo dado en el marco de ciertas posibilidades entendidas en un sentido a priori». Cfr. Krüger, op. cit., p. 46. Deja de ser necesario interpretar para darse una experimentación en primera persona.

32 Fedro, 245 y ss.

33 En consonancia con todo esto cfr. Timeo, $40 \mathrm{~d}$ y ss. donde se critica la noción tradicional de dios a partir del tratamiento irónico del mito; Fedón, 821 y Banquete 250 c y ss. donde se critica la corporalidad, no como crítica a los aspectos anímico o corporal del hombre mismo, sino en tanto que rendición pasional del alma a las necesidades del cuerpo como una mala orientación del Eros de esta hacia lo material y no hacia lo divino. La filosofía debe ser renuncia de esa corporalidad para pasar a ser, como se recoge en Fedón, 64 a, práctica del «morir y del estar muerto».

34 Timeo, $29 \mathrm{c}-\mathrm{d}$. 
«el alma debe saber que está abocada aquí al mito, porque sabe que no es dueña de sí misma $»^{35}$.

En este sentido cabe una comparación del nuevo mito de Eros y los antiguos dioses cósmicos. Platón utiliza los mitos porque está de acuerdo con la religión tradicional en el punto de tener en cuenta la dependencia esencial del hombre. No obstante, a diferencia de esta vieja mitología Platón tomará conciencia de dicha dependencia y del lenguaje mítico en sí mismo llegando más allá que el propio paganismo. A través del personaje de Fedro ${ }^{36}$ se narra cómo hasta entonces nadie se había atrevido a celebrar nunca a Eros como merece el dios tan «desconocido». El dios por el cual comprender la filosofía no es uno oficial, no es un dios conocido y adorado por todos.

La figura clásica reservada para el amor no era Eros sino su madre, Afrodita. Eros se presenta clásicamente como mero acompañante y sirviente de su madre. Krüger dirá que «el pagano verdaderamente "piadoso" olvida la propia pasión en favor del poder que la produce: "desprecia" a Eros a favor de su madre Afrodita ${ }^{37}$. Tomar conciencia de Eros es percatarse de la libertad propia, romper con la dependencia absoluta del poder ajeno y, en ese sentido, desprenderse de la religión pagana que «desperdicia a Eros en favor de Afrodita». Y es que lo que venimos exponiendo desde hace unos párrafos no se limitará al ámbito de la pasión; afectará a todo lo humano -deficitario y dependiente-. El mito de Eros en Platón no puede ser mito como lo era Afrodita en el paganismo clásico; tan solo queda ya interpretar a los dioses antiguos -incomprensibles como el Dios Cristiano para la ilustración moderna- en la medida en que se internan en el mundo del propio Eros: asumiendo la incomprensión. Platón partirá para ello del hombre y no de la idea de kósmos. El deseo del amante hacia el amado permite interiorizar a las ajenas divinidades de la mitología antigua pues, para Krüger: «aquel del que el amante se quiere apoderar ya no es inmediata manifestación de un dios, sino algo que nos lo recuerda (erinnern) $)^{38}$.

Quienes adoran a Eros están liberados del poder de los dioses antiguos, pero habrán de sentir, de nuevo, un poder que los atrapa por cuanto sean conscientes de su presencia. Hay una liberación respecto del azar, que no es esencia del hombre sino mero acontecer: ese hombre liberado por Eros pasará a ser dueño de su propio comportamiento y, consecuentemente, se volverá responsable de sus actos. Y, puesto que la inspiración de los dioses es la que da lugar al conocimiento, será a partir de esta por la cual se desarrollará el concepto de $\operatorname{arte}^{39}(t e ́ k h n \bar{e})$-que da razón de por qué, por ejemplo, en la Apología ${ }^{40}$ los artesanos son mejores que los poetas-.

La tékhne, no obstante, permite a uno volverse dueño de su comportamiento; pero no de sí mismo. Se necesita de la alabanza a la locura erótica, que implicará

\footnotetext{
Cfr. Krüger, op. cit., p. 50.

Banquete, 177 a y ss.

Cfr. Krüger, op. cit., p. 55.

Ibid., p. 63.

39 Este concepto se desarrolla en Platón a la contra de la interpretación sofística del mismo. La «menesterosidad» humana por la cual el hombre es dependiente se plantea como innegable: mientras que la ilustración entenderá que tal dependencia es externa al propio comportamiento y que solamente afecta a un conjunto no esencial de hechos - afectando tan solo a la materia del comportamiento pero no al comportamiento en sí-, para Platón, entendiendo que el comportamiento en sí es la manera en como el hombre se hace cargo de su naturaleza misma, la manera más específica de comportarse en relación con lo que condiciona no será soberana -no hay independencia absoluta-, sino que ninguna actitud racional ofrece de suyo respuesta a la cuestión acerca de si también el comportamiento en su conjunto se funda en dicha racionalidad.

40 Apología, 22 b-d.
} 
asumir que lo que queremos en el conjunto de nuestra vida se sitúa más allá de nuestros propios horizontes. Y esa asunción, que ha de pasar por la fragilidad del desconcierto, solamente desconcierta, en verdad, si nos obcecamos en ser dueños de la última instancia desde la que ejercer el dominio propio. El dominio de la razón sobre las pasiones sólo es el ingenuo dominio de las afecciones concretas del sentimiento; no de la dominación reflexiva del dominio mismo -y, por tanto, del hombre en general-. Se reconocerá que la pasión es el condicionante de los estados de aquella menesterosa existencia al encontrar la significatividad de la racionalidad -ni mítica ni poética- restringida a la esfera de lo artístico - o técnico- abriendo camino, precisamente, hacia un fin (télos) dominante.

Eros, por tanto, no embotará el pensamiento; lo alentará. Se aleja así Platón del paganismo, donde el alma se sitúa en las cosas entregándose a ellas y siendo guiada por sus poderes personales. El alma ahora se halla dentro de sí misma; separada de las cosas de las que tiene necesidad. Si los dioses antiguos inspiraban el deseo y lo guiaban, ahora el camino lo debe abrir y recorrer uno mismo. El Eros platónico no se conducirá de por sí al amado, sino que habrá de ir «de aquí para allá buscándolo» ${ }^{41}$. Para Krüger esto es lo que se pone en juego cuando Diotima enuncia ${ }^{42}$ los atributos de Eros -en tanto que hijo del recurso (póros) - como los del hombre liberado del mito antiguo $^{43}$. En este nuevo mito platónico la ilustración adopta la forma tradicional a expensas de la menesterosidad última experimentada religiosamente.

Con todo esto presente, Krüger analiza algunas de las cuestiones más problemáticas $^{44}$ de los diálogos platónicos proponiendo su re-lectura desde esta nueva concepción de mýthos ${ }^{45}$. A partir del mýthos platónico se estructura la idea de que para nosotros la verdad a través del lógos es una cuestión demasiado elevada ${ }^{46}$.

41 Banquete, $209 \mathrm{~b}$.

42 Ibid., 203 b-c.

43 Ansioso de conocimiento (phronéseōs epithymētēs), abundante en recursos (pórimos), amante de la sabiduría toda su vida (philosophōn dià pantòs tô̂ bîou), etc.

44 Como una nueva interpretación del daîmon socrático o la estructuración de la idea con la que culmina la obra de Krüger acerca del porqué de la forma dialógica -indirecta- de la obra platónica. Los diálogos siempre son presentados de forma indirecta; las conversaciones -re-producidas- no afectan directamente al lector. En República, 392 c y ss. se analizan dos clases de los modos de hablar (léxis) del poeta. Por un lado está la narración simple (haplê diégēsis) -en la que el poeta no se esconde-, que es la mejor para la poesía auténtica; por otro la imitación (mímésis) -donde el poeta se olvida de sí mismo y del asunto que es su competencia para elaborar-. La clave para Platón consistirá en reducir esta última al mínimo pero sin hacerla desaparecer del todo. En los dramas tal estilo mimético será nocivo, y es que la empatía respecto de la hegemonía trágica del páthos ajena debe evitarse. Así, el diálogo platónico se estructurará imitando paradójicamente personajes que invitan a la autonomía evitando siempre la ilusión dramática -por eso el estilo indirecto-. Otra cuestión relevante, la ausencia del propio Platón en toda su obra escrita, no sería, en esta misma línea interpretativa, otra cosa más que la precaución de no ser tomado él como narrador: siempre escuchamos a otros que no nos narra a nosotros directamente sino a un tercero. Platón evita inducirnos al olvido de nosotros mismos por la imitación así como renuncia a encadenarnos a una relación nosotros-filósofo que escribe. Pasamos a ser meros testigos de un diálogo presentado de forma directamente dramática acerca del diálogo que se va a narrar. Platón trata de evitar el peligro que supone la literatura no solamente queriendo no decirnos nada sino, además, evitando aprovechar su superioridad narrativa evitando que se nos diga a través de otro cualquiera -ya que ni siquiera Sócrates tendrá la verdad-. A través de esta idea estructurada en torno a la idea de mito y, en concreto, de Eros, se entienden también sus palabras de Carta VII, 341 c: «desde luego no hay ni habrá nunca una obra mía que trate de estas cosas». Krüger dirá al respecto que: «es por esta razón por la que el Banquete también podría representar, por medio de la esencia de Eros y de manera más concreta, la esencia del tipo de obra literaria de la que es ejemplo» cfr. Krüger, op. cit., p. 118.

$45 \quad$ Nueva en dos sentidos: en tanto que Platón la compone rompiendo desde ella con la tradición y en tanto que Krüger la propone como objeto de estudio de forma que se plantee como un acceso panorámico a la filosofía platónica. Nueva para los contemporáneos de Platón por estructurarse frente al mýthos tradicional y nueva para nosotros por proponerse como clave interpretativa.

46 Por ello en la analogía de República, 376 e y ss. se habla del hijo o vástago del Sol pero nunca del padre. 
Los mitos serán tratados en Platón con ironía por cuanto se dirá que son falsos, pero no de manera absoluta, sino «en general falsos (hōs tò hólon eipeîn psê̂dos) aunque también haya en ellos algo de verdad (éni dè kaì alêthê)». No es posible dar cuenta del contenido de los mitos porque lo que dicen, debido a su misma naturaleza, no puede ser conocido a través del lógos. Lo que importa aquí, ese «algo de verdad» que contienen -análogo a la revelación hesiódica-, es su sentido general -y no, por el contrario, su pretensión figurada concreta-. No obstante, para Krüger, «a pesar de todo se puede y se debe cometer el "atrevimiento" de expresar, de forma figurada, pero convincente (dado "que las cosas son así o de una forma similar"), lo que sobrepasa nuestra comprensión discursiva y afecta a lo particular» ${ }^{47}$.

$\mathrm{Si}$ en el Fedón ${ }^{48}$ se insiste en que debemos invocar a nuestro niño interior a diario, y que Sócrates es buen invocador en ese sentido, a ese invocar pertenecerán tanto el lógos como el mýthos unidos indisolublemente. El nuevo mýthos asegura la independencia del pensamiento de forma que prohíbe la huída al antiguo mito ingenuo ${ }^{49}$. Eros es la unidad de la ingenuidad y la reflexión en el nuevo mito capaz de conjugar poesía y verdad; conjunción que permite entender esa concepción del mýthos como juego ${ }^{50}$. Esa dualidad permite estructurar a Eros como un mero mediador y no como algo absoluto. El mito platónico resaltará el momento de la inadecuación dada por la limitación de quien solamente estará legitimado a calificar de sabios (sophói) a los dioses. Así se relega al hombre a la aspiración, al ensalce de Eros frente a tal calificación, al amor: la calificación de philo-sophós.

El nuevo mito recogerá ese carácter filosófico y se edificará en su lenguaje aporético -irreducible tanto a una mera expresión del fracaso de la razón como a una simbología de los elementos de la irracionalidad humana-. Ese lenguaje llevará consigo, ahora, el tema de hablar acerca de lo que constituye el propio tema del mito: la evidencia, el mostrar aquello a lo cual el lógos no puede acceder pero que ha de tener presente en cada uno de los pasos de su búsqueda. Puesto que ese lógos apunta más allá de sí mismo, se embarca en la pretensión de adentrarse en lo que le es ajeno y para poder hacerlo debe contar con un guía -que se inserte, precisamente, en esa otredad-. El mito de Eros muestra el fin al que la técnica del pensamiento debe subordinarse; ese saber como aquello a lo que se aspira que no podrá, a su vez, ser un saber en sentido estricto. Ese saber que ha de ser verdadera opinión, correcta opinión (orthé dóxa). Noción que Krüger desentraña desvelando como el punto de conexión entre la idea de mýthos platónica, su concepción de filosofía y el papel que Eros jugará en ella; esa noción que permitirá entender y cerrar el nuevo trato que Platón hace de la noción de mýthos como, precisamente, el acceso a los diálogos que muestran el despliegue más amplio posible de su propio contenido.

\section{Referencias bibliográficas}

Burnet, John. Platonis Opera: Recognovit Brevique Adnotatione Critica Instruxit. Oxford, 1900-1907. (Las obras de Platón se citan siguiendo esta edición e indicando solamente las cifras y letras correspondientes).

\footnotetext{
47 Krüger, op. cit., p. 101.

Fedón, 77 e.

Cfr. supra. Nota a pie de página 42 .

50 Leyes, 803 e.
} 
Gadamer, Hans-Georg. Philosophische Lehrjahre. Frankfurt, 1977.

Krüger, Gerhard. Einsicht und Leidenschaft: Das Wesen des platonischen Denkens. Frankfurt, 1974.

Krüger, Gerhard. Eros y mito en Platón. Traducción de Miguel Oliva Rioboó y Santiago Sanjurjo. Madrid, 2017

Natorp, Paul. Platos Ideenlehre; eine Einführung in den Idealismus. Leipzig, 1903.

Stenzel, Julius. Studien zur Entwicklung der Platonischen Dialektik von Sokrates zu Aristoteles: arete und diairesis. Princeton, 1917.

Bibliografía secundaria

Halfwassen, Jens. Der Aufstieg zum Einen: Untersuchungen zu Platon und Plotin. Berlín, 2006.

Martínez Marzoa, Felipe. Ser y Diálogo. Madrid, 1996

Prauss, Gerold. Platon und der logische Eleatismus. Berlín, 2012.

Rehn, Rudolf. Sprache und Dialektik in der Aristotelischen Philosophie. Ámsterdam, 2000.

Wyller, Egil A. Platons Parmenides in seinem Zusammenhang mit Symposion und Politeia: Interpretationen zur platonischen Henologie. Wurzburgo, 2007. 